\title{
Delivery and integration of MEGARA at GTC: the process of going from laboratory to the telescope
}

Pérez-Calpena, Ana, García-Vargas, Marísa-Luisa Luisa, Gil de Paz, Armando, Castillo Morales, África, Martínez Delgado, Ismael, et al.

Ana Pérez-Calpena, Marísa-Luisa Luisa García-Vargas, Armando Gil de Paz, África Castillo Morales, Ismael Martínez Delgado, Manuel Maldonado, Ernesto Sánchez-Blanco Mancera, Ainhoa Sánchez, Antonio Verdet, Bertrand Lefort, Sergio Pascual, Andres Curto, Oscar García, Xabier Arrillaga, Ignacio Carrera, Eider Gonzalez, Jesús Gallego, Esperanza Carrasco Licea, Jorge Iglesias-Páramo, Raquel Cedazo, "Delivery and integration of MEGARA at GTC: the process of going from laboratory to the telescope," Proc. SPIE 10705, Modeling, Systems Engineering, and Project Management for Astronomy VIII, 107050A (10 July 2018); doi: 10.1117/12.2311903

Event: SPIE Astronomical Telescopes + Instrumentation, 2018, Austin, Texas, United States 


\title{
Delivery and integration of MEGARA at GTC: the process of going from laboratory to the telescope
}

\author{
Ana Pérez-Calpena ${ }^{\mathrm{a}}$, María-Luisa Luisa García-Vargas ${ }^{\mathrm{a}}$, Armando Gil de Paz $^{\mathrm{b}}$, África Castillo \\ Morales $^{\mathrm{b}}$, Ismael Martínez Delgado ${ }^{\mathrm{a}}$, Manuel Maldonado ${ }^{\mathrm{a}}$, Ernesto Sánchez-Blanco Mancera ${ }^{\mathrm{a}}$, \\ Ainhoa Sánchez ${ }^{\mathrm{b}}$, Antonio Verdet ${ }^{\mathrm{b}}$, Bertrand Lefort ${ }^{\mathrm{a}}$, Sergio Pascual ${ }^{\mathrm{b}}$, Andres Curto ${ }^{\mathrm{b}}$, Oscar García ${ }^{\mathrm{b}}$, \\ Xabier Arrillaga ${ }^{\mathrm{c}}$, Ignacio Carrera ${ }^{\mathrm{c}}$, Eider Gonzalez ${ }^{\mathrm{c}}$, Jesús Gallego ${ }^{\mathrm{b}}$, Esperanza Carrasco Licea ${ }^{\mathrm{d}}$, \\ Jorge Iglesias-Páramo $^{\mathrm{e}}$, Raquel Cedazo ${ }^{\mathrm{f}}$ \& MEGARA team \\ ${ }^{a}$ FRACTAL S.L.N.E, C/ Tulipán 2, Portal 13 1A, E-28231, Las Rozas de Madrid, Spain; \\ bepartmento de Física de la Tierra y Astrofísica, Facultad de CC. Físicas, Universidad \\ Complutense de Madrid, Plaza Ciencias, 1, E-28040, Madrid, Spain; \\ ${ }^{\mathrm{c}}$ AVS, Pol. Ind. Sigma Xixilion Kalea 2, Bajo Pabellón 10, E-20870, Elgoibar, Gipuzkoa, Spain; \\ d Instituto Nacional de Astrofísica, Óptica y Electrónica, Luis Enrique Erro \#1, Tonanzintla, Puebla, \\ 72840, Mexico; \\ e Instituto de Astrofísica de Andalucía, Glorieta de Astronomía s/n, E-18008, Granada, Spain; \\ ${ }^{\mathrm{f}}$ Escuela Técnica Superior de Ingeniería y Diseño Industrial (ETSIDI), C/ Ronda de Valencia, 3, E- \\ 28012, Madrid, Spain;
}

\begin{abstract}
MEGARA is an IFU \& MOS medium-resolution spectrograph that finished its commissioning at the GTC 10m telescope on August 2017. MEGARA is a fiber-fed high-resolution spectrograph with two major units, Fiber-MOS \& Spectrograph, that are now located at the Folded-Cass F and Nasmyth-A foci of GTC respectively. These are linked by more than 1200 fibers $44.5 \mathrm{~m}$-length split between two observing modes, the LCB (Integral Field Unit, IFU) and a MultiObject (MOS) capability with 92 robotic positioners each one provided with a mini-bundle of 7 fibers. The spectrograph can accommodate 18 VPHs (11 of them can be simultaneously mounted) covering the visible wavelength range at Resolving Powers between $\mathrm{R}=6000-20000$. This paper presents the sequence of tasks carried out after Laboratory Acceptance at the Universidad Complutense de Madrid to move the whole instrument to the GTC. A detailed day-to-day plan was followed to disassemble, pack, transport, reintegrate the full instrument at the GTC and to verify performance to ensure the instrument was ready for commissioning. The lessons learnt are relevant to other double-focus instruments being developed such as WEAVE@WHT orPFS@Subaru.
\end{abstract}

Keywords: MEGARA, GTC, integral field unit (IFU), multi-object spectrograph (MOS), fiber bundles, packing, delivery, integration, verification

\section{INTRODUCTION}

MEGARA (Multi Espectrógrafo en GTC de Alta Resolución para Astronomía) is an optical fiber-fed spectrograph for the GTC $10.4 \mathrm{~m}$ telescope placed in the island of La Palma (Canary Islands, Spain). The MEGARA focal plane subsystems are located at the Folded Cassegrain F focal station. The fiber bundles drive the light from the focal plane to the spectrograph, hosted at the Nasmyth A platform (see Figure 1).

The instrument works in the optical range from $3700 \AA$ to $9800 \AA$ and offers two observing modes: Integral Field Unit (IFU), named Large Compact Bundle (LCB), and Multi-Object Spectrograph (MOS). Both modes are fed by $100 \mu \mathrm{m}$ fiber-core multimode optical fibers. The IFU provides a FOV of $12.5^{\prime \prime} \times 11.3^{\prime \prime}$, while the MOS is able to place up to 92 mini-bundles of 7-fibers each covering a sky area of $3.5 \mathrm{arcmin} \times 3.5 \mathrm{arcmin}$. Eight additional minibundles with 7 fibers each located at the edge of the $3.5 \times 3.5 \operatorname{arcmin}^{2}$ FOV (shown in orange at Figure 2) to provide sky subtraction for the

Modeling, Systems Engineering, and Project Management for Astronomy VIII

edited by George Z. Angeli, Philippe Dierickx, Proc. of SPIE Vol. 10705

107050A · @ 2018 SPIE · CCC code: 0277-786X/18/\$18 
LCB mode. The science light comes into the spectrograph by means of a $44.5 \mathrm{~m}$ fiber optic wiring, which is routed through the Folded Cassegrain F rotator cable wrap, the elevation ring, the Nasmyth A elevation cable wrap and below the Nasmyth platform until reaching the spectrograph entrance position (see Figure 1).

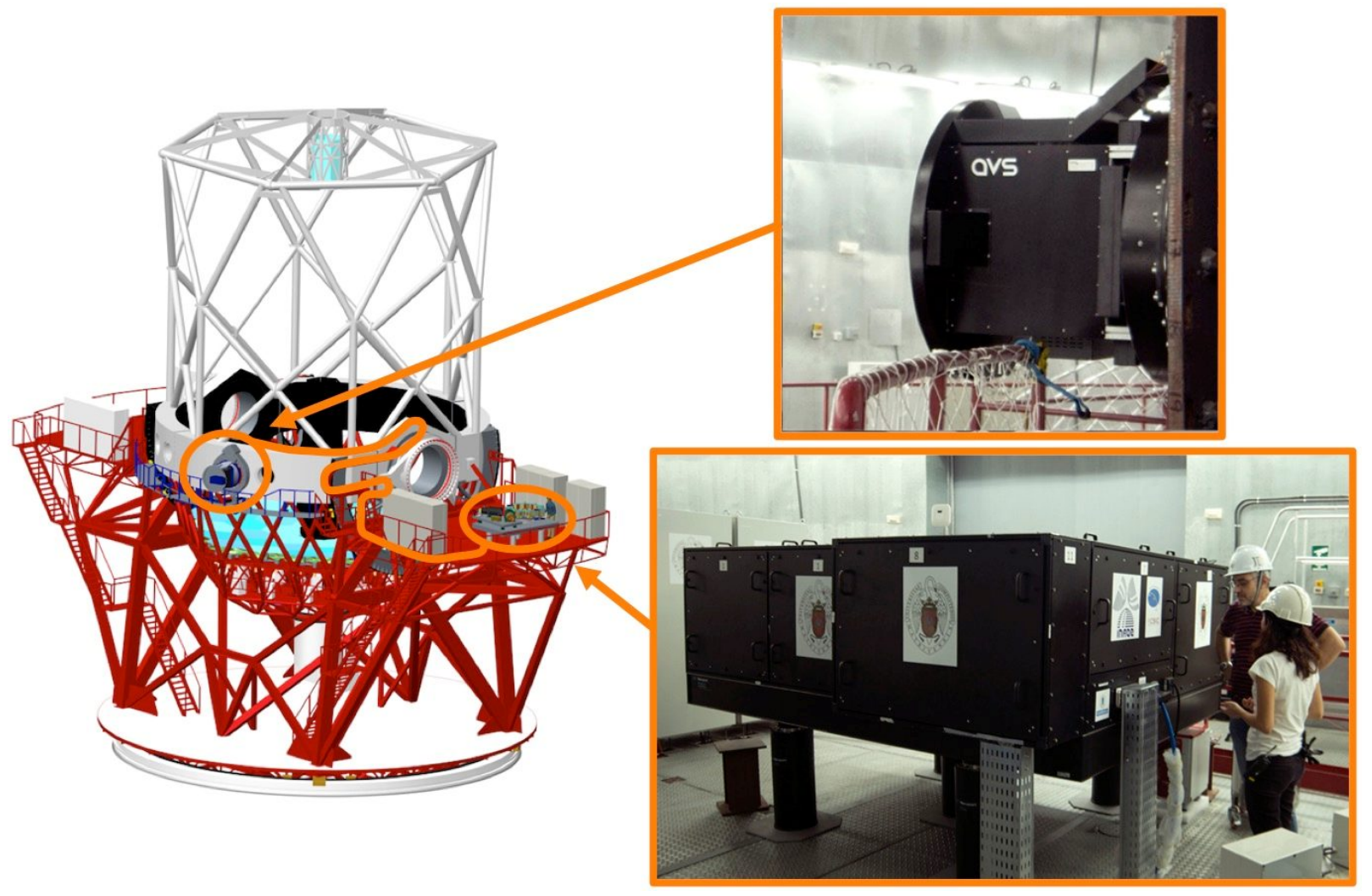

Figure 1: On the left, a GTC 3D model with MEGARA Folded Cassegrain subsystems integrated at FC-F focal station and MEGARA spectrograph at the Nasmyth A platform. On the right, views of the real MEGARA subsystems already integrated at the GTC.

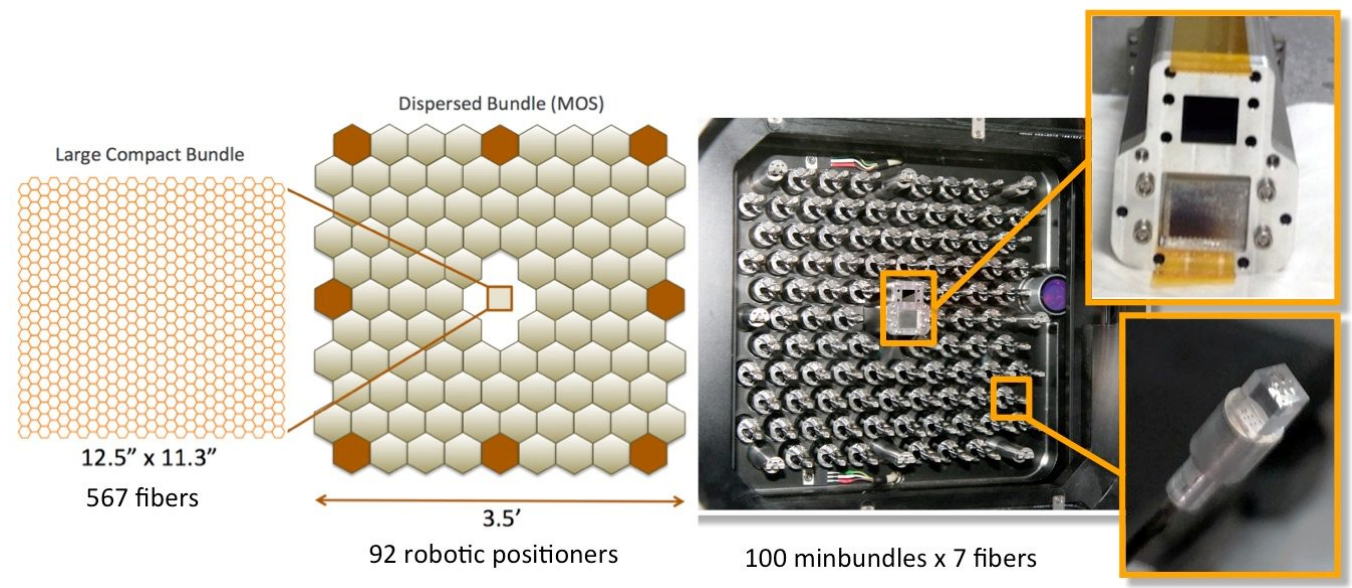

Figure 2: Left: MEGARA FOV layout. Right: View of the real focal plan and details of the LCB and minibundles microlens arrays.

At the focal plane entrance, LCB and MOS fibers are telecentrically illuminated with the aim of a field lens (Figure 3). Micro-lens arrays are coupled to the bundles to reduce the telescope focal ratio from F17 to F3 (Figure 2). Subsequently each fiber bundle will be allocated at the spectrograph focal plane forming a smoothly curved pseudo-slit $110 \mathrm{~mm}$ length with a radius of curvature of $1075 \mathrm{~mm}$. More details can be found at [4] and [5]. 


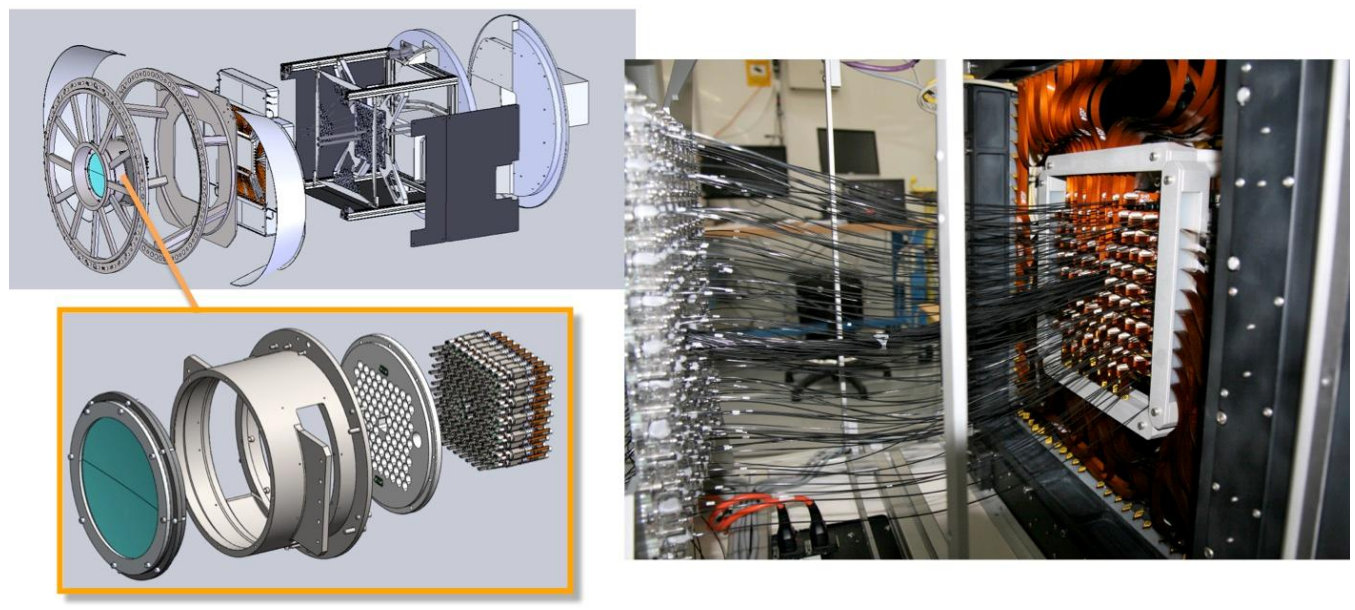

Figure 3: Left: section of the Folded Cassegrain subsystems assembly and an exploded view of the optical components. Right: View of the minibundles arrangement inside the FiberMOS assembly.
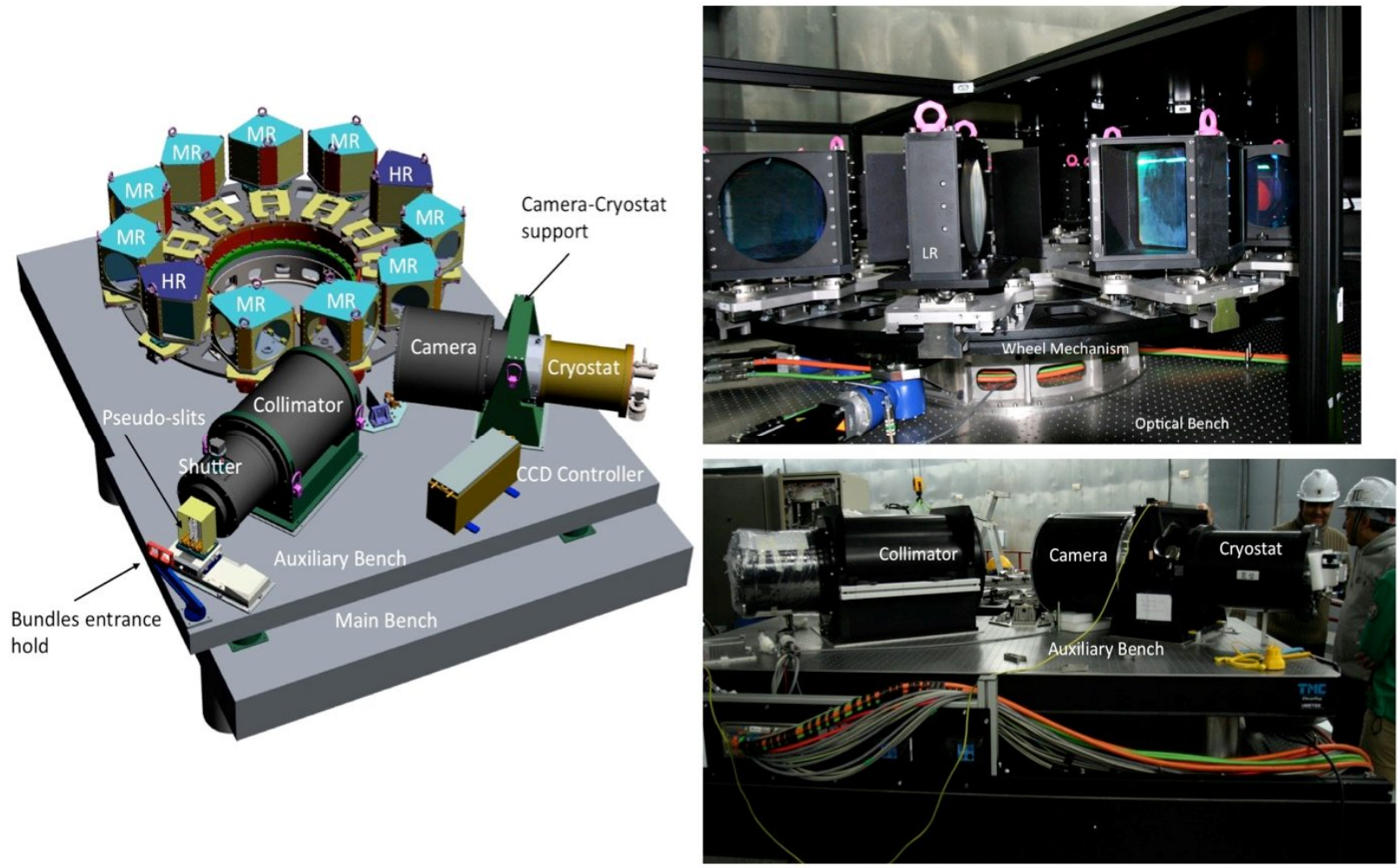

Figure 4: Left: MEGARA 3D spectrograph components view. Right: Photos taken during the spectrograph integration.

The spectrograph (Figure 4) is an all-refractive system (with F3 and F1.5 focal ratios for the collimator and camera respectively) using a set of interchangeable gratings that are based on Volume Phase Hologram gratings (VPHs) placed at the collimated beam (where the pupil of the system is formed), see [6] and [7]. The final set of VPHs is composed by 18 gratings which offer three spectroscopy modes with Low Resolution (LR; 6 VPHs), Medium Resolution (MR; 10 VPHs) and High Resolution (HR; 2 VPHs), corresponding to $\mathrm{R}_{\mathrm{FWHM}}=6000,12000$, 18700 (resolution required by design), respectively. A subset of 11 gratings is simultaneously mounted on the instrument wheel, so that available for the same observing night. Finally, the scientific data will be recorded by means of an e2V CCD231-84 model 4096 $\times$ $409615 \mu \mathrm{m}$-pixels deep-depleted CCD detector. Table 1 summarizes MEGARA main characteristics. See also R.1 
Table 1: Main characteristics of MEGARA LCB IFU and MOS modes

\begin{tabular}{|c|c|c|c|}
\hline \multicolumn{2}{|c|}{ PARAMETER } & \multicolumn{2}{|c|}{ REQUIREMENTS } \\
\hline \multicolumn{2}{|c|}{ Telescope } & \multicolumn{2}{|c|}{ GTC } \\
\hline \multicolumn{2}{|c|}{ Plate Scale } & \multicolumn{2}{|c|}{$0.82 \mathrm{~mm} \mathrm{arcsec}^{-1}$} \\
\hline \multicolumn{2}{|c|}{ Field Lens } & \multicolumn{2}{|c|}{$\mathrm{D}=260 \mathrm{~mm}$} \\
\hline \multicolumn{2}{|c|}{ Microlens } & \multicolumn{2}{|c|}{$\begin{array}{c}\text { Hexagonal Shape } \\
\text { F\# transformation from F17 to F3 }\end{array}$} \\
\hline \multirow{2}{*}{\multicolumn{2}{|c|}{ Fiber Unit }} & \multicolumn{2}{|c|}{$\begin{array}{c}\text { Folded Cassegrain focus } \\
\text { Field lens for telecentric illumination } \\
\text { LCB, MOS }\end{array}$} \\
\hline & & Large Compact Bundle & MOS Bundle \\
\hline \multicolumn{2}{|c|}{ Fiber-core } & $100 \mu \mathrm{m}$ & $100 \mu \mathrm{m}$ \\
\hline \multicolumn{2}{|c|}{ No. of fibers } & 623 & 644 \\
\hline \multicolumn{2}{|c|}{ Spaxel } & $0.62^{\prime \prime}$ & $0.62^{\prime \prime}$ \\
\hline \multicolumn{2}{|c|}{ FOV } & $12.5^{\prime \prime} \times 11.3^{\prime \prime}$ & $3.5^{\prime} \times 3.5^{\prime}$ \\
\hline \multicolumn{2}{|c|}{$\Delta \lambda\left(\mathbf{E E D}_{\mathbf{8 0}}\right)$} & 4.0 pix & 4.0 pix \\
\hline \multicolumn{2}{|c|}{$\Delta \lambda(\mathbf{F W H M )}$} & 3.6 pix & 3.6 pix \\
\hline \multirow{3}{*}{$\mathbf{R}$} & LR & 6000 & 6000 \\
\hline & MR & 12000 & 12000 \\
\hline & HR & 18700 & 18700 \\
\hline \multicolumn{2}{|c|}{ Pseudo-slit } & \multicolumn{2}{|c|}{$110 \mathrm{~mm}$ long $\& \mathrm{ROC}=1075 \mathrm{~mm}$} \\
\hline \multicolumn{2}{|c|}{ F-ratios } & \multicolumn{2}{|c|}{ Collimator F3 to camera F1.5 } \\
\hline \multicolumn{2}{|c|}{ Pupils size } & \multicolumn{2}{|c|}{$160 \mathrm{~mm}$} \\
\hline \multicolumn{2}{|c|}{ Gratings } & \multicolumn{2}{|c|}{ VPHs, $240 \mathrm{~mm} \times 190 \mathrm{~mm}(\mathrm{MR}, \mathrm{HR}), 220 \mathrm{~mm} \times 180 \mathrm{~mm}(\mathrm{LR})$, selectable } \\
\hline \multicolumn{2}{|c|}{ Wavelength coverage } & \multicolumn{2}{|c|}{$3700 \AA-9800 \AA$} \\
\hline \multicolumn{2}{|c|}{ Detector } & \multicolumn{2}{|c|}{ e2V CCD231-84 model, $4 \mathrm{k} \times 4 \mathrm{k}$ pixels $15 \mu \mathrm{m}$ in size, astro $2 \mathrm{AR}$ coated } \\
\hline
\end{tabular}

The Universidad Complutense de Madrid (UCM), in Madrid (Spain) leads the MEGARA Consortium, which is also composed by Instituto Nacional de Astrofísica, Óptica y Electrónica (INAOE) in Puebla (México), Instituto de Astrofísica de Andalucía (IAA-CSIC; Granada, Spain) and Universidad Politécnica de Madrid (UPM; Spain). The MEGARA Science Team includes line-up expert researchers encompassing different astronomical areas from exoplanets and cool stars to cosmology, going through massive stars, planetary nebula, and nearby galaxies, coming from MEGARA consortium and different institutions in Spain, Mexico and the University of Florida (Gainesville, USA).

MEGARA was developed under contract with GRANTECAN, the public company responsible for GTC instrument development, maintenance and operation. The main project milestones since GTC published the Announcement of Opportunity on March 2009 until MEGARA was commissioned at the end of August 2017 are shown at Table 2. It is relevant to mention that the funds for the final design and building of the instrument came almost 4 years after the selection and that the construction contract of the instrument was signed on 2014 May $5^{\text {th }}$ and, from that date, the instrument was manufactured, integrated, tested and shipped to GTC in less than 3 years. The economical effort done by the MEGARA Consortium and associated companies was crucial to keep the project alive during these unfunded time.

The detailed plan for MEGARA Laboratory Acceptance was presented and approved at the Pre-laboratory Acceptance Review on February 2015. This System Verification plan at laboratory of the Universidad Complutense de Madrid (named Laboratorio de Instrumentación Cientifica Avanzada, LICA) included the description of all the verification tests that must be carried out to show MEGARA high-level requirements fulfillment before delivering the instrument to the GTC. The plan was composed by 47 tests, including preliminary tests to verify cryostat and mechanism performance, detailed characterization of each instrument set-up (measurement of focus position, spectral lines, central wavelength and spectral coverage, full width half maximum across the full detector, resolving power, ghost analysis, etc.) of both LCB and MOS modes and with each VPH unit, and an end-to-end test to verify the MEGARA control system capabilities and other additional tests requested by GRANTECAN to verify the instrument maintainability. 
Table 2: Main MEGARA project milestones.

\begin{tabular}{|l|l|}
\hline \multicolumn{1}{|c|}{ Date } & \multicolumn{1}{c|}{ Historical record } \\
\hline March 2009 & GTC Announcement of Opportunity \\
\hline 21-July-2010 & MEGARA presents Conceptual Design \\
\hline 28-September-2010 & MEGARA is selected to move to PD phase \\
\hline 16-June-2011 & Preliminary Design (PD) contract signed \\
\hline 21-September-2012 & PD review \& Delta-PD review passed \\
\hline 04-February-2013 & Optical Critical Design signed \\
\hline 02-May-2013 & Optical Critical Design Review passed \\
\hline 28-April-2014 & Detailed Design contract signed \\
\hline 30-April-2014 & Detail design documentation delivery \\
\hline 05-May-2014 & MEGARA construction contract signed \\
\hline February 2015 & Pre-laboratory Acceptance Review passed \\
\hline February 2017 & Laboratory Acceptance Review \\
\hline 28-March-2017 & Arrival at the GTC \\
\hline March-April 2017 & Integration at GTC (4 weeks) \\
\hline May - June 2017 & Daytime commissioning (2 runs - 5 days each) \\
\hline June-July-August 2017 & Nighttime commissioning (3 runs - 10 nights each) \\
\hline 31-August-2017 & End of nighttime commissioning \\
\hline
\end{tabular}

The Laboratory Acceptance Review took place on February 2017. The documentation delivered for this review included the updated design documents and drawings, the acceptance reports of the subsystems, the results of the System Verification Plan described in the previous paragraph and the detailed plan for the integration, verification and commissioning of MEGARA at GTC.

After this review, MEGARA was dismounted and packaged to be shipped to GTC. This article describes the process that was followed to go from laboratory to the telescope until having MEGARA successfully installed, verified and working at GTC ready for operation, which will start on July $1^{\text {st }} 2018$.

\section{PACKING AND DELIVERY TO GTC}

MEGARA is a big instrument with optical fibers and very large optical components. The camera and collimator are composed by 5 and 7 lenses respectively (of different materials including Calcium Fluoride) with diameters up to $250 \mathrm{~mm}$. High- and medium-resolution VPHs are coupled to prisms for changing the angle of incidence while keeping fixed the main optics geometry and have large envelopes up to $240 \mathrm{~mm}$ x $340 \mathrm{~mm}$ x $190 \mathrm{~mm}$. The fragility of all these components was carefully considered for preparing the packing and shipping plan.

Packing and shipping was organized considering that MEGARA is physically composed by three main modules, which are the Folded-Cassegrain subsystems plus optical fibers, the spectrograph and the control cabinets. Besides, the auxiliary equipment that must be provided with the instrument had to be taken into account. The main considerations for packing and organizing these modules are explained in the following subsections.

\subsection{Packing of the Folded Cassegrain subsystems}

The Folded Cassegrain (FC) subsystems include: the field lens, the fiber optics for both modes (IFU and MOS, coupled to their respectively frames, robotic positioners and microlens arrays), all the mechanical parts (for supporting and protecting these optical components and providing fiber arrangement), the focal-plane cover (to provide the low crosstalk observations), the boresight telescope (to allow assessment of the instrument alignment with the telescope) and the electronic boxes containing the low-level control components required by the cover mechanism and the robotic positioners. Fiber optics for both the IFU and MOS modes are continuous from their attachment to the corresponding IFU frame, sky mini-bundles buttons and robotic positioners to the two pseudo-slit frames. They are glued in both ends and there are no intermediate connectors. The design decision was to keep the corresponding frames and positioners 
integrated at the focal plane mechanical frame (also called Fiber-MOS plate) and to dismount LCB and MOS pseudoslits frames at the spectrograph entrance. Therefore, all FC components, with the exception of the field lens that was dismounted and packed independently, were transported assembled.

A transportation structure (see Figure 5) was designed to allow secure transportation from the MOS manufacturer (AVS) to LICA and, afterwards, from LICA to GTC and, also, to provide a support structure for these subsystems during the integration and optical verification of the robotic positioners at LICA.
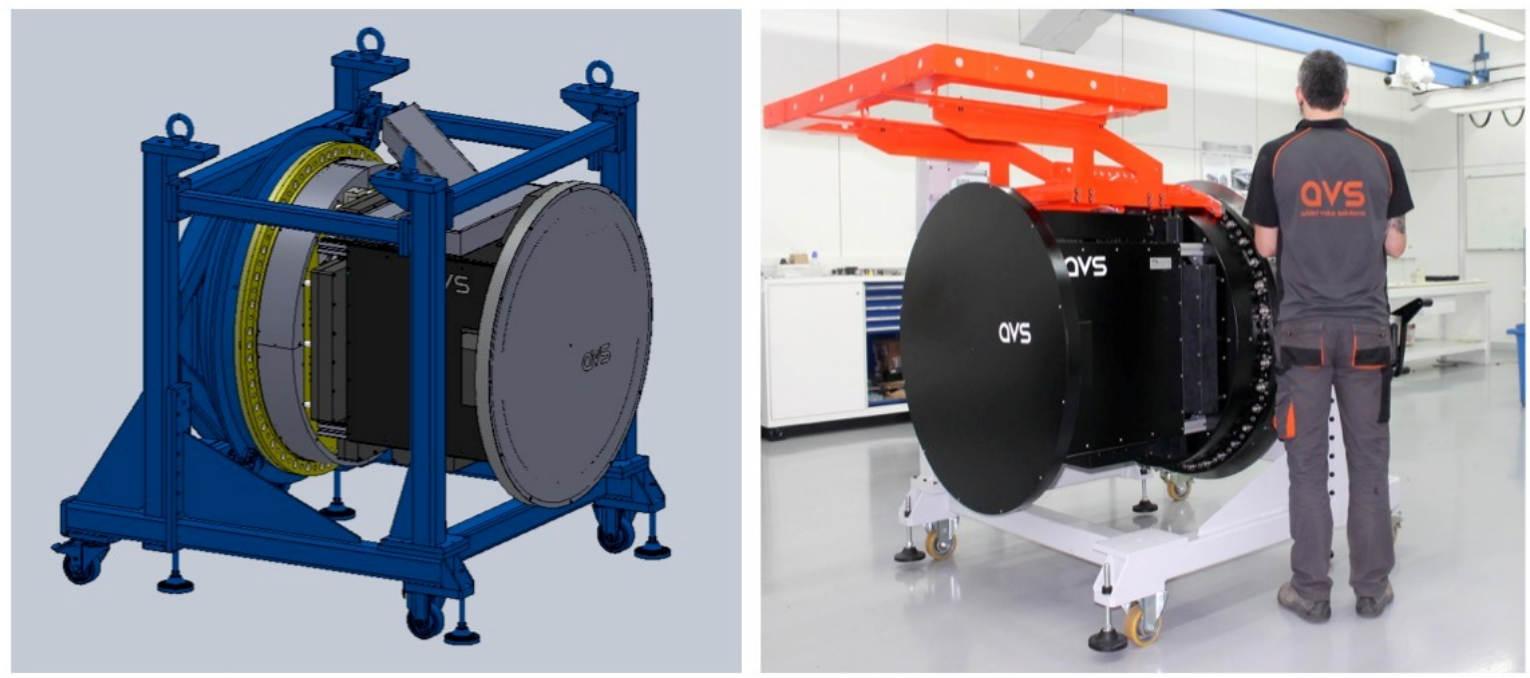

Figure 5: Left: 3D model of the FC auxiliary structure. Right: FC auxiliary structure with the fiber bundle box support attached.

IFU and MOS fiber bundles with pseudo-slit protective ends (see white frames at Figure 6 left) were packaged in their transportation box.

The fiber bundle box was attached to the fiber bundle box support (orange structure at Figure 6 center) to allow the crane handling the whole assembly to the FC subsystem transportation box. Them, the fiber bundle container was placed at the bottom (Figure 6 right) to reduce the height of the FC subsystem transportation box.
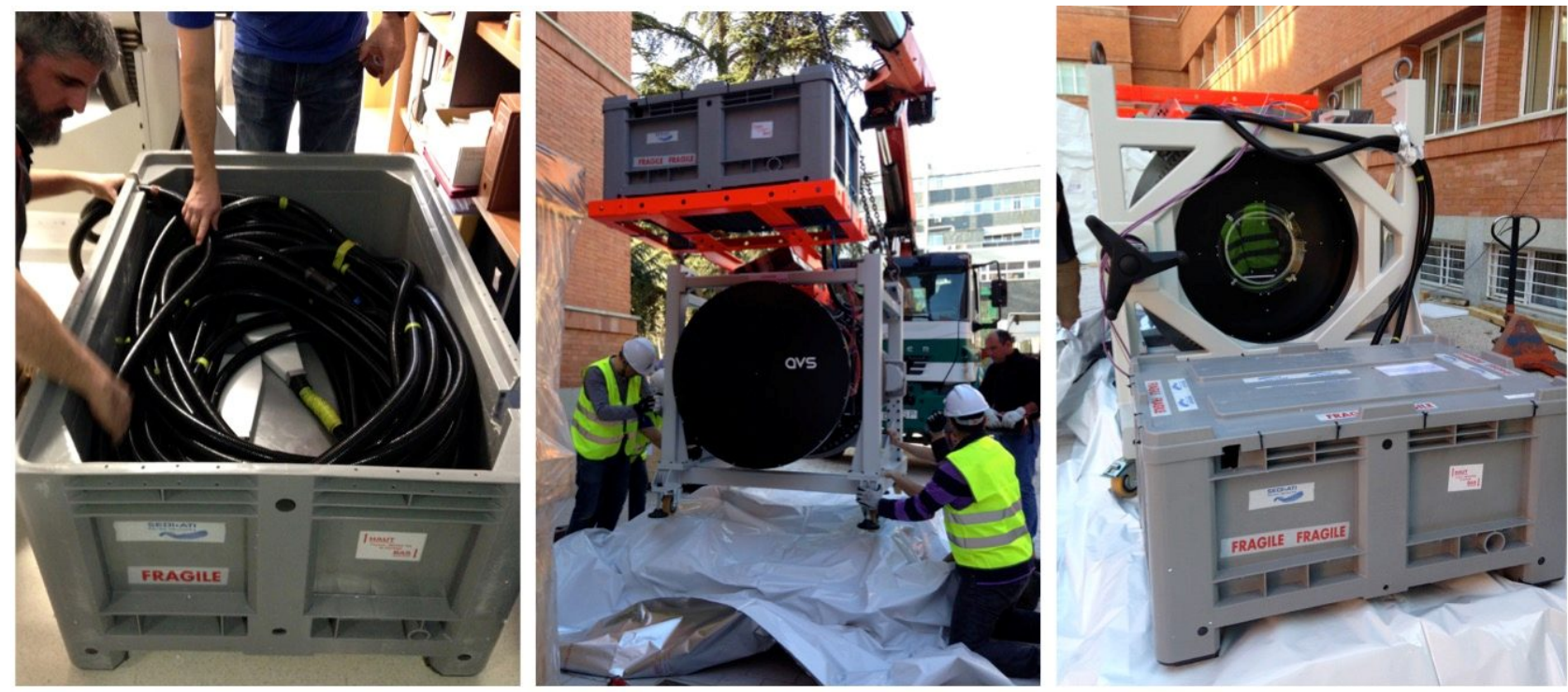

Figure 6: Left: Fiber bundles in its transportation box. Center: FC subsystems and fiber bundle box handled to its transportation box Right: FC subsystems in its transportation box in shipping configuration. 


\subsection{Packing of the spectrograph components}

The decision was to pack all spectrograph optical assemblies individually, leaving the grating selection mechanism (alias "the wheel") at the optical bench as well as the corresponding references to allow reintegrating all components in their positions at GTC without losing spectrograph alignment.

The following components were packaged individually:

- The main optical bench, which included the smaller optical bench for the main optics as well as the grating selection mechanism, was packed in a dedicated box. Interface plates and precise position references for the pseudo-slit mechanism, the collimator and the camera-cryostat assembly were kept at the smaller optical bench. In addition, the smaller optical bench, which is slightly standing out of the main one in its operational position (see Figure 4 left), had to be horizontally displaced to be in line with the main optical bench to not exceed the laboratory exit door aperture and to facilitate transportation and handling. Position references were added at the operating position. Besides, cables between spectrograph and electronic cabinets were disconnected at the electronic cabinets side and remains rolled up at the optical bench.
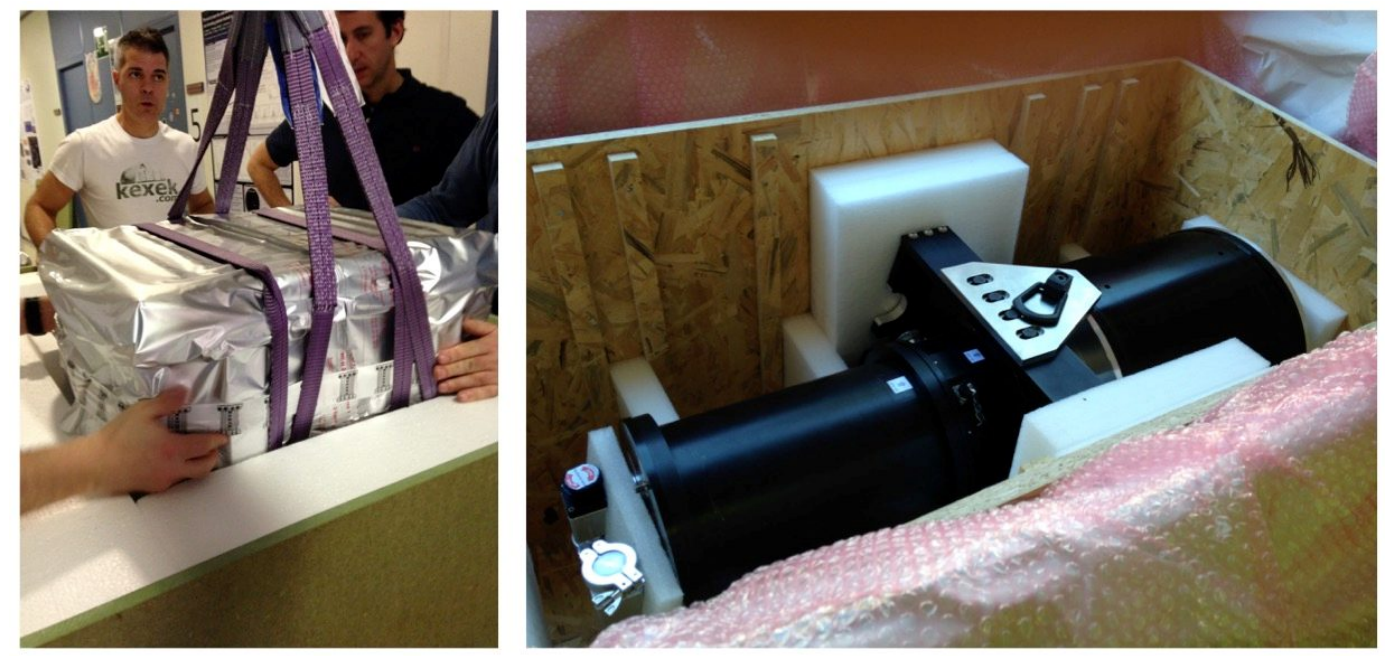

Figure 7: Left: Introducing a packed VPH grating in its transport box. Right: Camera-cryostat assembly in its transport box.

- The collimator was packed individually in one dedicated box with additional air-bag protection.

- The camera-cryostat was packed individually in one dedicated box with additional air-bag protection (see Figure 7). It must be noted that the last lens of the camera is the cryostat window. Therefore, this assembly must be transported together. Pressure sensors were removed from the cryostat leaving only the two valves that close the vacuum environment. The cryostat was kept at ambient temperature and in vacuum with the auxiliary pump connected until the day when it was packaged. At that day, the vacuum valve was closed and the pump packed.

- Each VPH grating was packed individually in a dedicated briefcase and, then grouped in four units in a box.

- The shutter was dismounted from the collimator and then packed.

- The pseudo-slit mechanism was packed.

- The CCD controller was packed.

- Main optical bench legs and cover were packed.

\subsection{Packing of the electronic cabinets}

The electronic cabinets (2) were transported fully mounted (i.e., all electronic components remain installed at both cabinets, only cables were disconnected and remains at the spectrograph and FC subsystems side) in dedicated boxes as shown in Figure 8. 

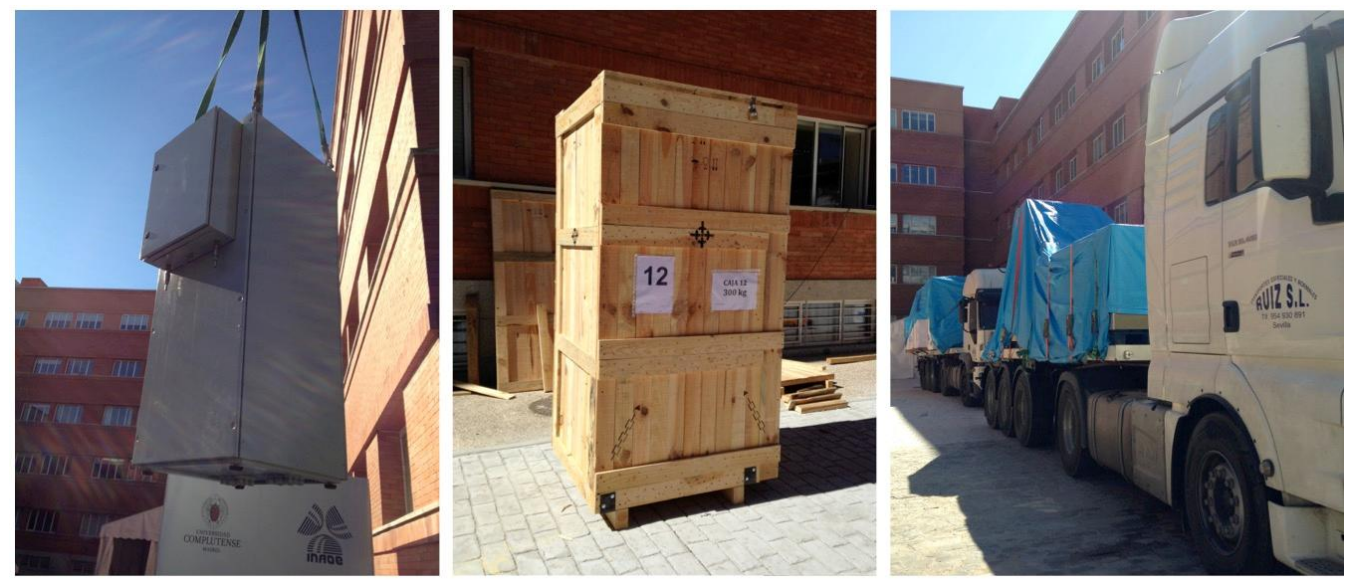

Figure 8: Left: Handling one electronic cabinet with the crane. Center: The same electronic cabinet in its container. Right: Trucks fully loaded ready to start the trip to the GTC.

\subsection{Packing of the auxiliary components}

Finally, all other components that must be provided with the instrument (as the vacuum pump and spares for GTC) and the auxiliary components that could be required for integration and verification of MEGARA were also packed.

The final packing list was composed by 23 boxes, being the larger box the one containing the optical bench. The envelope of this box was $3900 \times 3200 \times 1000 \mathrm{~mm}$. The second one was the FC subsystems box with an envelope of 2860 x $1700 \times 2200 \mathrm{~mm}$. Two trucks were required and a special permission had to be requested for the circulation of the truck hosting these two larger boxes as the width for normal circulation in Spain was exceeded.

The route followed between LICA laboratory at the Universidad Complutense (Madrid, Spain) and GTC (Observatorio del Roque de los Muchachos, La Palma, Canary Islands, Spain) included the road circulation from Madrid to Cádiz, boarding trucks platforms in a ship to La Palma and, finally, the road circulation from La Palma harbor to the GTC.

MEGARA was fully packed in 1 week, on March $13^{\text {th }}-17^{\text {th }}$ 2017. During this week other tasks that have been foreseen to ensure correct handling of the components from laboratory to the truck loading area (as removing laboratory wall panels to allow moving in horizontal position the optical bench) were done. The trucks were loaded at LICA on March $18^{\text {th }} 2017$ and arrived to La Palma on March $24^{\text {th }} 2017$. After coordination with the Head of GTC Operation and the local authorities at La Palma for special transportation approval, we did the last part of the trip, from La Palma harbor to the Observatory on March $28^{\text {th }}$, in a sunny day and with a clear road; arriving successfully at the GTC after a 2-hours trip.
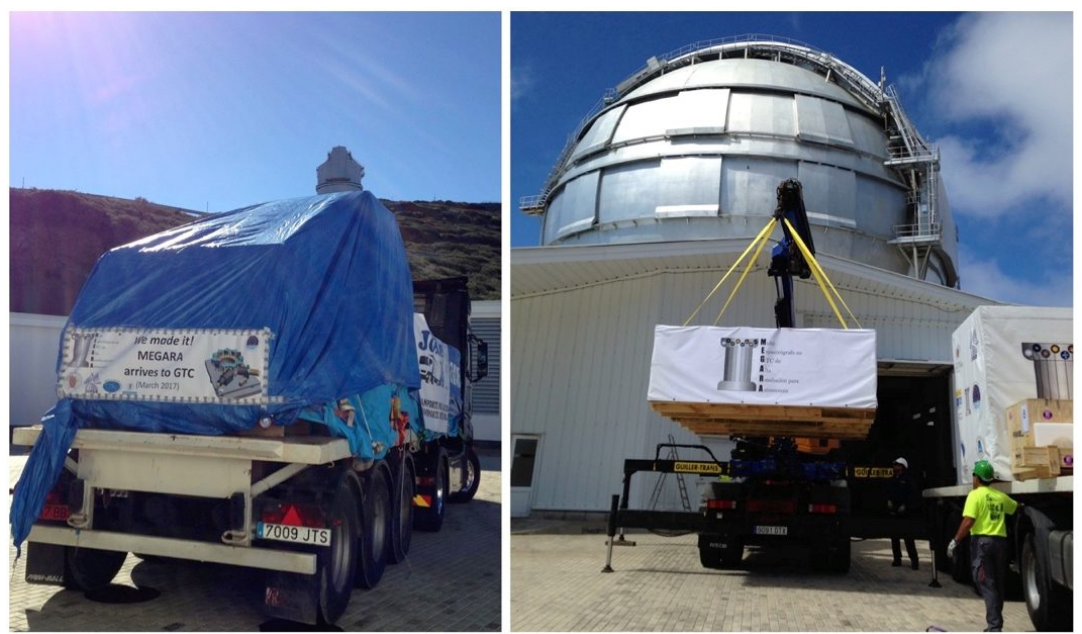

Figure 9: Left: First truck arriving to GTC. Right: Unloading the optical bench box. 


\section{MEGARA INTEGRATION AND VERIFICATION AT GTC}

As already mentioned at the introduction, the preparation of the MEGARA integration plan at the telescope started at the beginning of the construction phase. The integration plan was kept mainly in two documents. One document outlined the tasks to be performed to integrate the instrument at the telescope and included the calendar for carrying out these tasks, while the second one included the detailed description of the tasks. MEGARA integration tasks started after unpacking the instrument and finished after verification that the instrument was ready for starting commissioning.

The integration plan also identified the resources (manpower, equipment and supplies) that had to be available at GTC for carrying out the integration of the instrument and provided the estimation of the duration of the tasks. This document also included the prerequisites that had to be fulfilled by both MEGARA and GTC to be ready for starting the integration of the instrument at the telescope. The list of integration tasks, manpower and time estimated for each task is included in Table 3.

The document included the description of the integration tasks and their step-by-step detailed procedures, the tools, resources and responsible person to execute each task, and the precondition to be fulfilled and any additional technical information to support the execution of the tasks. Also, GTC resources (such as man lift platforms or cranes) needed to perform the activity were identified in advance. The results expected from the successful completion of the task were also detailed.

It was foreseen that the most complicate task was the integration of the FC assembly and the fiber bundles and, therefore, a detailed separate procedure was prepared for this activity. Two previous visits (June 2013 and July 2016) had been done by the MEGARA team to the GTC. The objective of the first visit was to measure the path to be followed by the optical fibers between the focal station FC-F and the spectrograph position at Nasmyth A and to identify any constrain in the path that must be considered at the design, as well as to close the final length. The second visit was organized in detail with the GTC operation team after iterating and approving a first draft procedure that was then executed to test the integration of a dummy FC assembly and dummy fiber bundles. The findings of that essay were very helpful to refine the procedure and have it ready for the real execution of this task.

Table 3: MEGARA Integration at GTC time plan.

\begin{tabular}{|c|c|c|c|}
\hline $\begin{array}{l}\text { Task code } \\
\text { AIV-TEC-MEG-046- }\end{array}$ & Task name & Personnel estimate & $\begin{array}{l}\text { Time } \\
\text { estimate } \\
\text { (hours) }\end{array}$ \\
\hline 3.2 .1 & $\begin{array}{l}\text { Integration of the Spectrograph Structure at the Nasmyth } \\
\text { platform }\end{array}$ & 5 MEGARA + 3 GTC & 4 \\
\hline 3.2 .2 & Integration of the collimator assembly & 5 MEGARA + 1 GTC & 3 \\
\hline 3.2 .3 & Integration of the camera-cryostat assembly & 5 MEGARA + 1 GTC & 3 \\
\hline 3.2 .4 & Integration of the pseudo-slit and focusing unit & 3 MEGARA + 1 GTC & 1 \\
\hline 3.2 .5 & Integration of the CCD controller & 2 MEGARA + 1 GTC & 1 \\
\hline 3.2 .6 & Integration of the pupil elements & 3 MEGARA + 1 GTC & 6 \\
\hline 3.2 .7 & $\begin{array}{l}\text { Integration of the spectrograph power, control cabinets, } \\
\text { electronic components and cabling }\end{array}$ & 3 MEGARA + 1 GTC & 16 \\
\hline 3.2 .8 & Integration of the spectrograph enclosure & 5 MEGARA + 1 GTC & 3 \\
\hline 3.1 .0 & $\begin{array}{l}\text { Preparation steps for the installation of the FC assembly and } \\
\text { fiber bundles. }\end{array}$ & 3 MEGARA + 1 GTC & 1.5 \\
\hline $\begin{array}{l}\text { 3.1.1, 3.3.1, 3.3.2, 3.3.3 } \\
\text { 3.3.4 (I) }\end{array}$ & $\begin{array}{l}\text { Integration of the FC assembly and fiber bundles up to the } \\
\text { Nasmyth platform }\end{array}$ & 3 MEGARA + 3-6 GTC & 9.4 \\
\hline 3.3 .4 (II), 3.1.2, 3.1.3 & $\begin{array}{l}\text { Integration of the fiber bundles up to spectrograph entrance } \\
\text { Focal frame tilt adjustment } \\
\text { FC Assembly power supply/ canBUS connection }\end{array}$ & 5 MEGARA + 3-6 GTC & 6.5 \\
\hline 3.4 .1 & MEGARA Control System SW components deployment & MEGARA + 1 GTC & 24 \\
\hline 3.5 .1 & Cryostat cooling-down & MEGARA + 1 GTC & 3 \\
\hline 3.5 .2 & MEGARA spectrograph alignment verification & MEGARA + 1 GTC & 5 \\
\hline 3.5 .3 & MEGARA Folded-Cassegrain subsystems tests & MEGARA + 1 GTC & 6 \\
\hline 3.5 .4 & Power shut down test & MEGARA + 1 GTC & 2 \\
\hline
\end{tabular}


These time estimates were considered together with GTC constrains (i.e. working days and daytime working hours) in order to prepare a detailed integration calendar that was discussed and agreed with the Head of GTC Operations. Table 4 summarizes the calendar that was agreed with GTC before shipping MEGARA.

Table 4: Detailed calendar of the MEGARA Integration at GTC plan.

\begin{tabular}{|c|c|c|c|c|}
\hline \multicolumn{5}{|c|}{ MEGARA INTEGRATION (WEEK 1 / 3) } \\
\hline Monday & Tuesday & Wednesday & Thursday & Friday \\
\hline 03-April-2017 & 04-April-2017 & 05-April-2017 & 06-April-2017 & 07-April-2017 \\
\hline 3.2 .1 & $\begin{array}{l}3.2 .2 \\
3.2 .3 \\
3.2 .4 \\
3.2 .5\end{array}$ & $\begin{array}{l}3.2 .6 \\
3.2 .7\end{array}$ & 3.27 & $\begin{array}{l}3.2 .7 \\
3.2 .8\end{array}$ \\
\hline \multicolumn{5}{|c|}{ EASTER HOLIDAYS } \\
\hline \multicolumn{5}{|c|}{ MEGARA INTEGRATION (WEEK 2 / 3) } \\
\hline Monday & Tuesday & Wednesday & Thursday & Friday \\
\hline 17-April-2017 & 18-April-2017 & 19-April-2017 & 20-April-2017 & 21-April-2017 \\
\hline 3.1 .0 & 3.1 .0 & $\begin{array}{c}3.1 .1,3.3 .1,3.3 .2 \\
3.3 .3,3.3 .4(\mathrm{I})\end{array}$ & $\begin{array}{c}3.3 .4(\mathrm{II}), \\
3.2 .2,3.2 .3\end{array}$ & Backup Day \\
\hline \multicolumn{5}{|c|}{ MEGARA INTEGRATION (WEEK 3 / 3) } \\
\hline Monday & Tuesday & Wednesday & Thursday & Friday \\
\hline 24-April-2017 & 25-April-2017 & 26-April-2017 & 27-April-2017 & 28-April-2017 \\
\hline 3.4 .1 & 3.4 .1 & $3.4 .1,3.5 .1$ & 3.5 .2 & $\begin{array}{l}3.5 .3 \\
3.5 .4\end{array}$ \\
\hline
\end{tabular}

This plan was then executed at GTC with minor variations compared to the tasks and schedule that were agreed between the MEGARA team and GRANTECAN prior to the execution of the tasks. During all the process the safety aspects were taken into account in great detail including the certification for working in "height" of members of our team that participated in the integration activities and having three team members certified as "Preventive human resources".

Some preparatory work outside the telescope chamber, which mainly including unpacking and testing the electronic cabinets cooling circuits, was done between March $29^{\text {th }}-31^{\text {st }}$ 2017. The integration tasks, as identified at the Integration plan, took place on April $3^{\text {rd }}-7^{\text {th }}\left(1^{\text {st }}\right.$ week $)$, April $18^{\text {th }}-21^{\text {st }}\left(2^{\text {nd }}\right.$ week $)$ and April $24^{\text {th }}-28^{\text {th }} 2017$ ( $3^{\text {rd }}$ week $)$, as scheduled.

The following tables summarizes per week when the tasks were finally performed and the task results.

Table 5: Summary of the MEGARA integration tasks execution. First week.

\begin{tabular}{|c|c|l|}
\hline \multicolumn{2}{|c|}{$1^{\text {st }}$ Integration week } \\
\hline Task code & Execution date & \multicolumn{1}{c|}{ Comments } \\
\hline 3.2 .1 & 03 April 2017 & $\begin{array}{l}\text { The spectrograph structure was unloaded from its transport box and moved to the telescope } \\
\text { chamber load elevator the previous week (on March } 31^{\text {st }} \text { ). } \\
\text { The optical bench legs positions, optical bench envelope and control cabinets positions were also } \\
\text { marked at the Nasmyth A platform the previous week. } \\
\text { The optical bench legs were first uploaded to the Nasmyth A and then the main optical bench. } \\
\text { Once attached to the legs, the small (auxiliary) optical bench was moved against the } \\
\text { corresponding references to its operating position. }\end{array}$ \\
\hline 3.2 .2 & 04 April 2017 & $\begin{array}{l}\text { The collimator was uploaded within its transport box to the dome platform in front of the } \\
\text { Nasmyth A platform and then for the box to the optical bench. The collimator was positioned } \\
\text { against its references and attached to its interface plate. } \\
\text { Note: The shutter was integrated at the collimator on April } 5^{\text {th }}\end{array}$ \\
\hline
\end{tabular}




\begin{tabular}{|c|c|l|}
\hline 3.2 .3 & 04 April 2017 & $\begin{array}{l}\text { The same procedure was applied to the camera-cryostat assembly. } \\
\text { Note: Cryostat pumping was started on April } 5^{\text {th }} \text { 2017. We verified that a low vacuum has been } \\
\text { kept during the transportation. }\end{array}$ \\
\hline 3.2 .4 & 05 April 2017 & $\begin{array}{l}\text { The pseudo-slit and focusing unit was attached against the corresponding references at its } \\
\text { interface plate in the auxiliary optical bench. }\end{array}$ \\
\hline 3.2 .5 & 05 April 2017 & The CCD controller was attached at the optical bench. \\
\hline 3.2 .6 & 06 April 2017 & $\begin{array}{l}\text { The 11 gratings that were to be used first during daytime commissioning were mounted: 6 LR } \\
\text { (Low Resolution), 2 HR (High Resolution), MR-U and MR-UB and MR-RI (MR, Medium } \\
\text { resolution). } \\
\text { The other 7 gratings were stored in their dedicated briefcase at the mirrors storing room. } \\
\text { Several grating changes were foreseen to be done during commissioning periods to perform } \\
\text { verification of all gratings in both LCB and MOS modes. }\end{array}$ \\
\hline 3.2 .7 & $5-6$ April 2017 & $\begin{array}{l}\text { The control cabinets were uploaded and integrated at the Nasmyth A. } \\
\text { The network, power and cooling circuits were connected. }\end{array}$ \\
\hline 3.2 .8 & 04 April 2017 & $\begin{array}{l}\text { The spectrograph enclosure was mounted after integration of the collimator and camera-cryostat } \\
\text { assembly at the optical bench to ensure that the optical components were well protected. We } \\
\text { installed first the cover provisionally for allowing night observations and repeated the process } \\
\text { the next day to guarantee a stable cover installation. }\end{array}$ \\
\hline
\end{tabular}
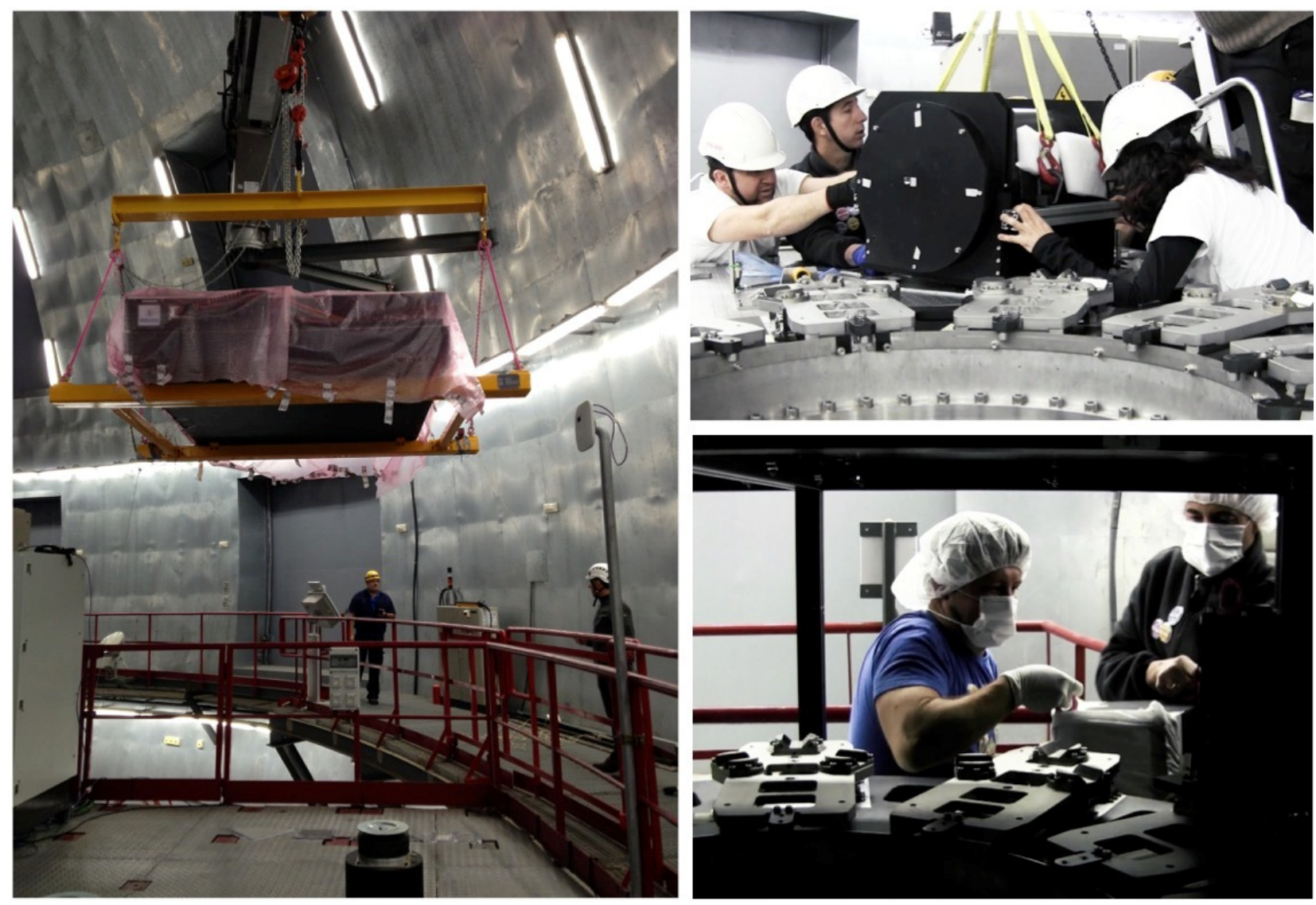

Figure 10: Left: Integration of the optical bench at the Nasmyth A platform. Right up: Integration of the collimator against its references. Right down: Mounting a grating at the spectrograph grating mechanism platforms. 
Table 6: Summary of the MEGARA integration tasks execution. Second week.

\begin{tabular}{|c|c|c|}
\hline \multicolumn{3}{|r|}{$2^{\text {nd }}$ Integration week } \\
\hline Task code & Execution date & Comments \\
\hline 3.1 .0 & $\begin{array}{l}\text { 3-7 April } 2017 \\
\text { 18 April } 2017\end{array}$ & $\begin{array}{l}\text { The FC assembly was unloaded from its transport box and moved to the instrumentation } \\
\text { laboratory on March } 30^{\text {th }} 2017 \text {. Preparatory works to verify the assembly at the laboratory } \\
\text { were performed during the first integration week and the April } 18^{\text {th }} 2017 \text {. }\end{array}$ \\
\hline $\begin{array}{l}3.1 .1,3.3 .1 \\
3.3 .2,3.3 .3 \\
3.3 .4(\mathrm{I})\end{array}$ & 19 April 2017 & $\begin{array}{l}\text { The FC assembly was moved to the telescope chamber and then integrated to the FC-F } \\
\text { position. The LCB and MOS fiber bundles and FC assembly control CanBUS were moved } \\
\text { from FC assembly to the FC platform and then routed from the FC-F focal station to the } \\
\text { Nasmyth A platform through the FC-F cable wrap, the elevation ring and the Nasmyth A } \\
\text { elevation cable wrap. The fiber bundle box transport box had been moved to the Nasmth A } \\
\text { platform in order to allow storing in the box the pseudo-slit ends and the length of the bundles } \\
\text { to be still installed below the Nasmyth A platform up to the spectrograph entrance position. }\end{array}$ \\
\hline 3.1 .3 & $\begin{array}{l}20 \text { April } 2017 \\
25 \text { April } 2017\end{array}$ & The FC assembly power supply and CanBUS were connected and verified. \\
\hline 3.1 .2 & $\begin{array}{l}20 \text { April } 2017 \\
26 \text { April } 2017\end{array}$ & $\begin{array}{l}\text { Alignment of the FC assembly axis with respect the FC-F rotator axis was verified. A } \\
\text { misalignment of the telescope optical axis with respect to the rotator axis was measured by the } \\
\text { MEGARA boresight telescope. This misalignment was confirmed by GTC staff. } \\
\text { FC assembly alignment verification is further explained at section } 3.1 \text {. }\end{array}$ \\
\hline 3.3 .4 (II) & 21 April 2017 & $\begin{array}{l}\text { LCB and MOS fiber bundles were routed below the Nasmyth A platform to the spectrograph } \\
\text { entrance. Then, LCB and MOS pseudo-slits were integrated at their corresponding positions } \\
\text { into the pseudo-slit unit. }\end{array}$ \\
\hline
\end{tabular}

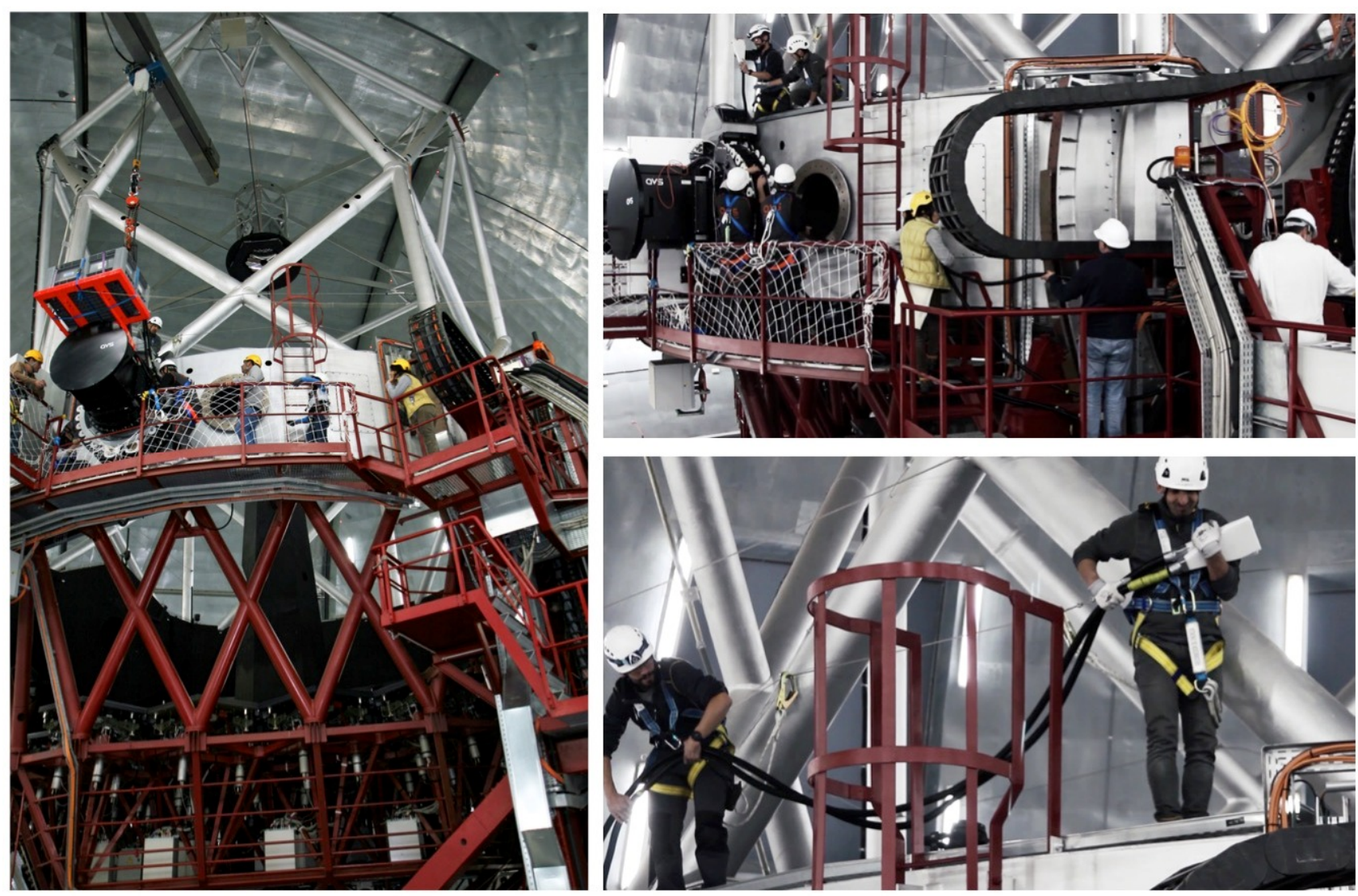

Figure 11: Left: Integration of the FC assembly. Right: Installing fiber bundles through the FC-F rotator cable wrap (up) and the elevation ring (down). 
Table 7: Summary of the MEGARA integration tasks execution. Third week.

\begin{tabular}{|c|c|c|}
\hline \multicolumn{3}{|r|}{$3^{\text {th }}$ Integration week } \\
\hline Task code & Execution date & Comments \\
\hline 3.4 .1 & $\begin{array}{l}\text { 24-28 April } 2017 \\
\text { Day and night } \\
\text { comm. }\end{array}$ & $\begin{array}{l}\text { The control system was integrated and tested with the objective to ensure that MEGARA was } \\
\text { operational to start commissioning. Part of the functionality could not be fully tested. In } \\
\text { particular, the following tasks were differed and verified during commissioning days: } \\
\text { (a) Part of the Fiber MOS functionality integrated at the GTC Control System (GCS). } \\
\text { (b) Focal Plane Cover integrated at the GCS. } \\
\text { (c) On-line Fiber MOS Positioning Tool (FMPT). } \\
\text { (d) Integrate the off-line (java-based) Fiber MOS Assignment Tool (FMAT). } \\
\text { MEGARA control system was verified to be ready to operate the instrument for } \\
\text { commissioning. }\end{array}$ \\
\hline 3.5 .1 & 24 April 2017 & $\begin{array}{l}\text { The cryostat had been pumped during almost } 3 \text { weeks and vacuum was well below } 1 \cdot 10^{-5} \mathrm{mbar} \\
\text { and, so, it was ready to be cooled down. When operational temperature was reached, pump } \\
\text { was switched off and the stability of temperature and vacuum was verified. } \\
\text { MEGARA cryostat was ready for operation. }\end{array}$ \\
\hline 3.5 .2 & $\begin{array}{l}27 \text { April } 2017 \\
\text { Day and night } \\
\text { comm. }\end{array}$ & $\begin{array}{l}\text { Calibration images using arc and halogen lamps were taken at the MEGARA detector to check } \\
\text { FWHM and focus. } \\
\text { MEGARA spectrograph alignment was verified. } \\
\text { Spectrograph alignment verification is further described in section } 3.2 \text {. } \\
\text { Repeatability of the pseudo-slit mechanism was also measured (a similar value as that obtained } \\
\text { at the LICA laboratory was obtained). } \\
\text { Other repeatability and position verification tests were differed and verified during } \\
\text { commissioning days: } \\
\text { - Repeatability of the grating mechanism. } \\
\text { - Verification of the LCB, MOS and shutter positions. } \\
\text { The off-line pipeline was also verified and used to process images during integration. } \\
\text { The on-line pipeline was integrated and verified during commissioning. }\end{array}$ \\
\hline 3.5 .3 & $\begin{array}{l}27 \text { April } 2017 \\
\text { Day and night } \\
\text { comm. }\end{array}$ & $\begin{array}{l}\text { LCB fibers were fully illuminated. One fiber (out of } 623 \text { ) was found to be not transmitting. } \\
\text { MOS fibers could not be fully illuminated because the provisional Instrument Calibration } \\
\text { Module (ICM) provided by GTC for integration illuminates the LCB but not the complete } \\
\text { MOS field of view. } \\
\text { MOS fiber link was tested during commissioning. We had already identified during fiber link } \\
\text { manufacturing and then at the integration with the microlens at the laboratory that } 2 \text { fibers (out } \\
\text { of } 644 \text { ) were not transmitting (within the admissible tolerance). We verified at GTC that all } \\
\text { other MOS fibers were working. }\end{array}$ \\
\hline 3.5 .4 & $\begin{array}{l}\text { 24-28 April } 2017 \\
\text { Day and night } \\
\text { comm. }\end{array}$ & $\begin{array}{l}\text { Power shut down test was not fully completed during the integration and was finalized during } \\
\text { commissioning. The following tests were performed: } \\
\text { - The emergency stop was activated while a mechanism was moving to verify that, after } \\
\text { activating power again, the device of the mechanism came back to idle state as required. } \\
\text { - All mechanism recovered from unknown positions performing homing. } \\
\text { - The RESCUE function (that allow parking Fiber MOS positioners from an unknown } \\
\text { position) was also successfully tested. }\end{array}$ \\
\hline
\end{tabular}

\subsection{MEGARA Folded Cassegrain assembly alignment verification}

The MEGARA Folded-Cassegrain assembly position in the $\mathrm{x}$ and $\mathrm{y}$ axes and the rotation in the $\mathrm{z}$ axis (optical axis) were not critical. Mechanical tolerances provided by manufacturing were requested enough to reach the required position and it was foreseen to calibrate the system pointing during commissioning using a reference star to know accurately the centers of the LCB and MOS frame.

The z-axis position had been measured with respect to the FC assembly interface plane during manufacturing to be at the nominal focal station position provided by the interface with GTC within a tolerance better than $\pm 100 \mu \mathrm{m}$. It was also foreseen to verify telescope focus during commissioning and, in any case, moving M2 would compensate it. 
The critical error for verifying MEGARA FC optical assembly was to verify the $x$-y plane tilt and, for this reason, a boresight telescope had been designed and integrated at the MOS focal frame and adjustment screws to tilt and move in $\mathrm{z}$ axis the MOS frame had been included as part of the FC assembly, see [4].

The boresight telescope provided an image of M2 central hole (Figure 12 left). While keeping the FC-F rotator at $0^{\circ}$ position, the boresight telescope was rotated in $\mathrm{z}$ axis and images were taken in each angle (Figure 12 center). Then, the FC-F rotator was rotated to different angles and another set of images were taken (Figure 12 right).

The center of the boresight rotation was found at coordinates $(662,489)$ of the commercial CCD camera attached to the boresight telescope while the center of the rotator FC-F rotation was found at coordinates $(663,490)$. Considering that the boresight camera scale plate is $0.21 \mathrm{arcmin} / \mathrm{pixel}$, we concluded that the tilt between the FC assembly axis and the FC-F rotator axis was below 0.5 arcmin. Our requirement was to be below $0.03^{\circ}(1.8 \mathrm{arcmin})$ so no additional adjustment was needed.

We also found that the rotator axis described a 24-pixels radius circle. This meant that the FC-F rotator axis had a tilt with M2 axis (i.e. with the telescope optical axis at the FC-F focal station) of 5 arcmin.
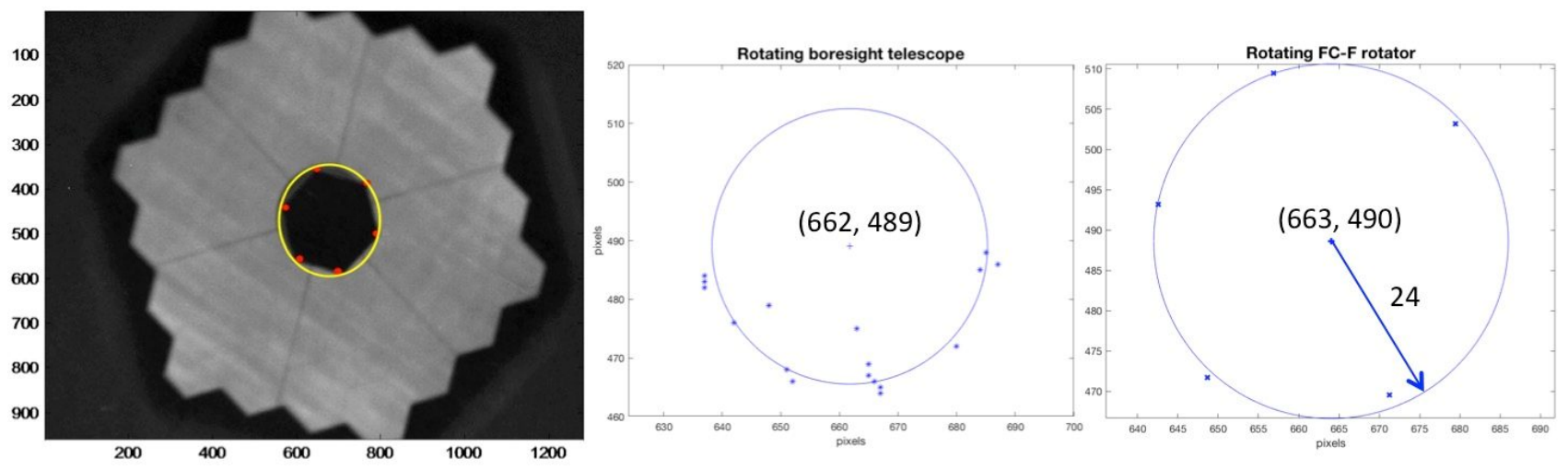

Figure 12: Left: MEGARA Boresight telescope view of GTC secondary mirror. Center: M2 centers when boresight telescope was rotated. Right: M2 centers when FC-F rotator was rotated.

\subsection{MEGARA spectrograph alignment verification}

Before moving to commissioning we needed to verify that the spectrograph main optics had been correctly aligned after being integrated against the mechanical reference added before dismounting the optical assemblies at the laboratory for being packed. In case that the spectrograph had not be found correctly aligned (e.g. references had been moved during transportation), the spectrograph alignment process followed at the laboratory had been repeated at GTC. The alignment targets and telescope used at laboratory were included between the auxiliary components transported with MEGARA to be able to repeat this task, which would have required around 4 working days.

To start spectrograph alignment verification, it was needed that the FC assembly had been integrated and verified, wavelength and continuum calibration lamps were available at the provisional Instrument Calibration Module, ICM, and the cryostat and control system were operative. Then, spectrograph was ready to take calibration images in the LCB mode. Several arc and halogen images were taken several gratings around the estimated focusing position. Focus must be adjusted per grating and temperature moving the fibers, pseudo-slit position, at the spectrograph entrance. The aim was to produce a look-up table to be used by the control system for automatically performing this adjustment considering the grating selected and the ambient temperature.

Focus images were reduced using the MEGARA pipeline, which provides (per image) the value of the best-fitting FWHM and focus within boxes of $100 \times 100$ pixels along all detector field of view. In addition, to have an independent evaluation to the pipeline of the image quality and optimal focus, raw images were also analyzed using identification and fitting tasks within the Figaro STARLINK package at 7 fibers per image.

As shown at Figure 13, the conclusion was that average FWHM value (3.4 pixels) was similar (slightly better) than measured at the laboratory and below the requirement (3.6 pixels). 


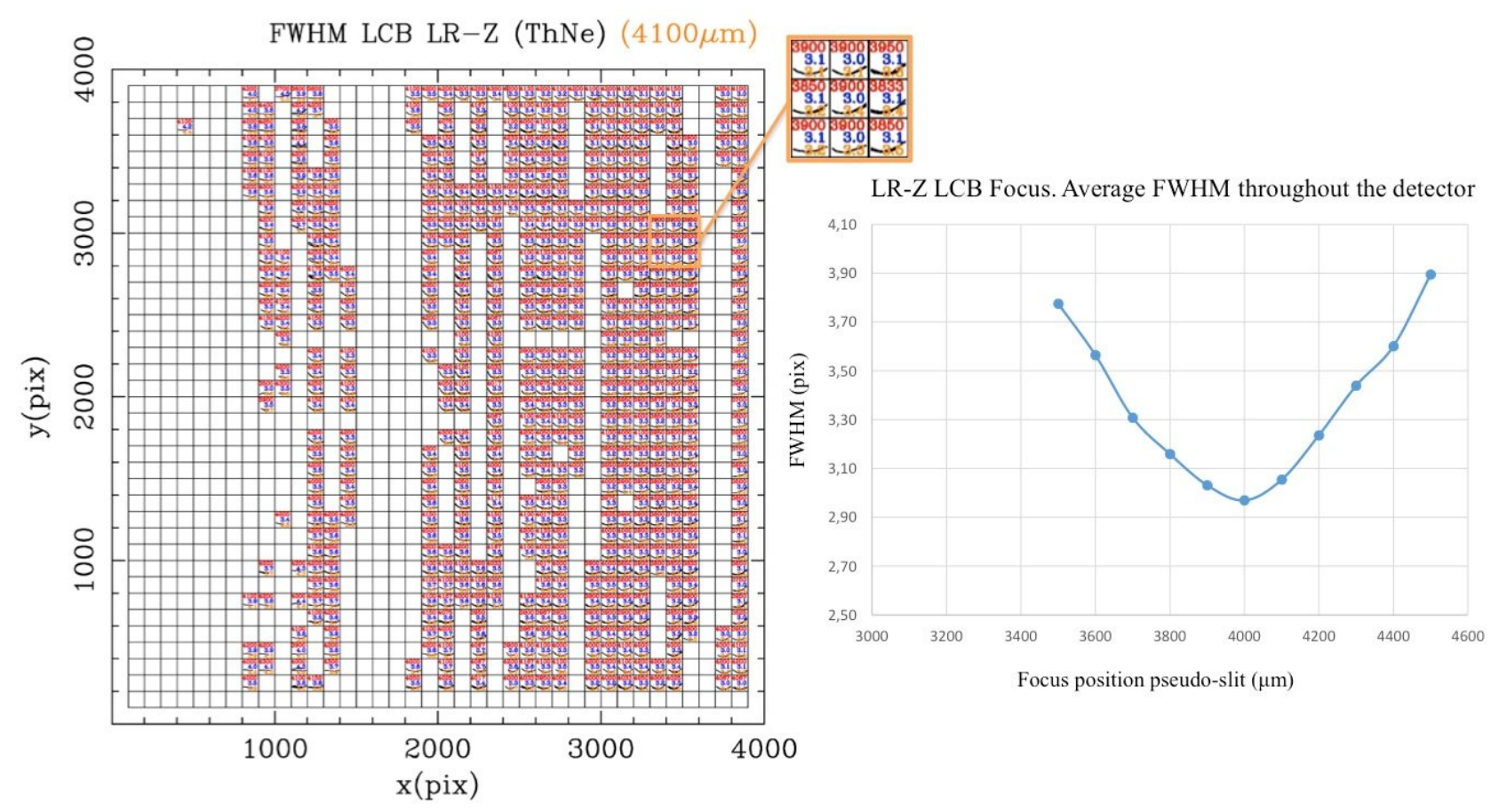

Figure 13: Left: LCB LR-Z FWHM measured with the pipeline at best-focus position. Right: LCB LR-Z focus measurements at several pseudo-slit positions.

\section{MEGARA COMMISSIONING}

The MEGARA Commissioning plan included all tests to be done at the GTC during daytime and nighttime periods in order to verify that MEGARA fulfills the High-level instrument requirements included at the MEGARA specification. The commissioning tests were linked to the MEGARA requirements at the system level verification matrix.

The tests were divided in daytime and nighttime tests and allocated to the 5 runs assigned by GTC:

- Daytime run 1, 40 working hours (one week) from May $8^{\text {th }}$ to May $12^{\text {th }} 2017$.

- Daytime run 2, 40 working hours (one week) from June $5^{\text {th }}$ to June $9^{\text {th }} 2017$.

- Nighttime run 1, 10 nights (7 hours each) from June $24^{\text {th }}$ to July $3^{\text {rd }} 2017$.

- Nighttime run 2, 10 nights (7 hours each) from July $24^{\text {th }}$ to August $2^{\text {nd }} 2017$.

- Nighttime run 3, 10 nights (7 hours each) from August 22 ${ }^{\text {nd }}$ to August $31^{\text {st }} 2017$.

The integration and commissioning team was composed by a total of 28 people on-site (in total during the different periods) from UCM, INAOE, IAA and participating companies FRACTAL and AVS with the remote support of the rest of the team.

The daytime commissioning included the following tests:

- Verify spectrograph mechanisms repeatability.

- Verify LCB and MOS pseudo-slits and shutter positions.

- Verify fiber-to-fiber uniformity for both LCB and MOS modes.

- Verification of the best focus spectrograph position.

- Best estimate of focus curve with temperature. 
- Recommendation of ICM configuration and calibration exposure times per grating.

- Perform wavelength calibration per grating.

- Verify central wavelength, spectral range, spectral resolution and linear dispersion per grating.

- Verify calibrations for Pipeline per grating.

- Verify ghosts and artifacts per grating.

- Verify scattering level per grating.

A total of 851 images were taken during daytime commissioning (506 with the LCB and 345 with the MOS), which corresponds to 530,431 spectra (see images distribution per grating at Figure 14). Besides, more than 1000 movements were performed with the spectrograph mechanisms and more than 50,000 movements with the MOS robotic positioners.

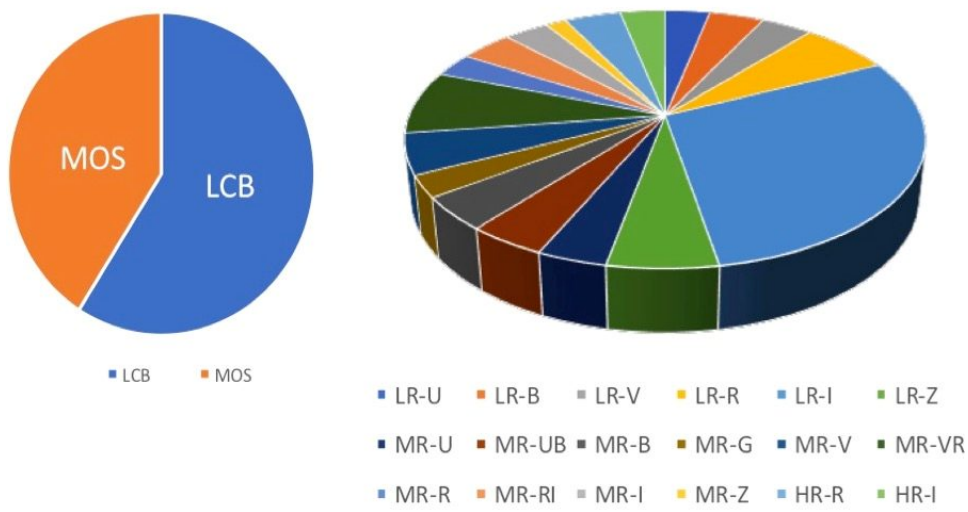

Figure 14: Daytime commissioning statistics.

These tests allowed characterizing all grating set-ups in both LCB and MOS modes and to provide best-focus curve for any VPH \& temperature to be set automatically by the MEGARA control system. Figure 15 shows the measured resolution for each grating in both LCB and MOS modes. See R.2 for more details about the commissioning results.
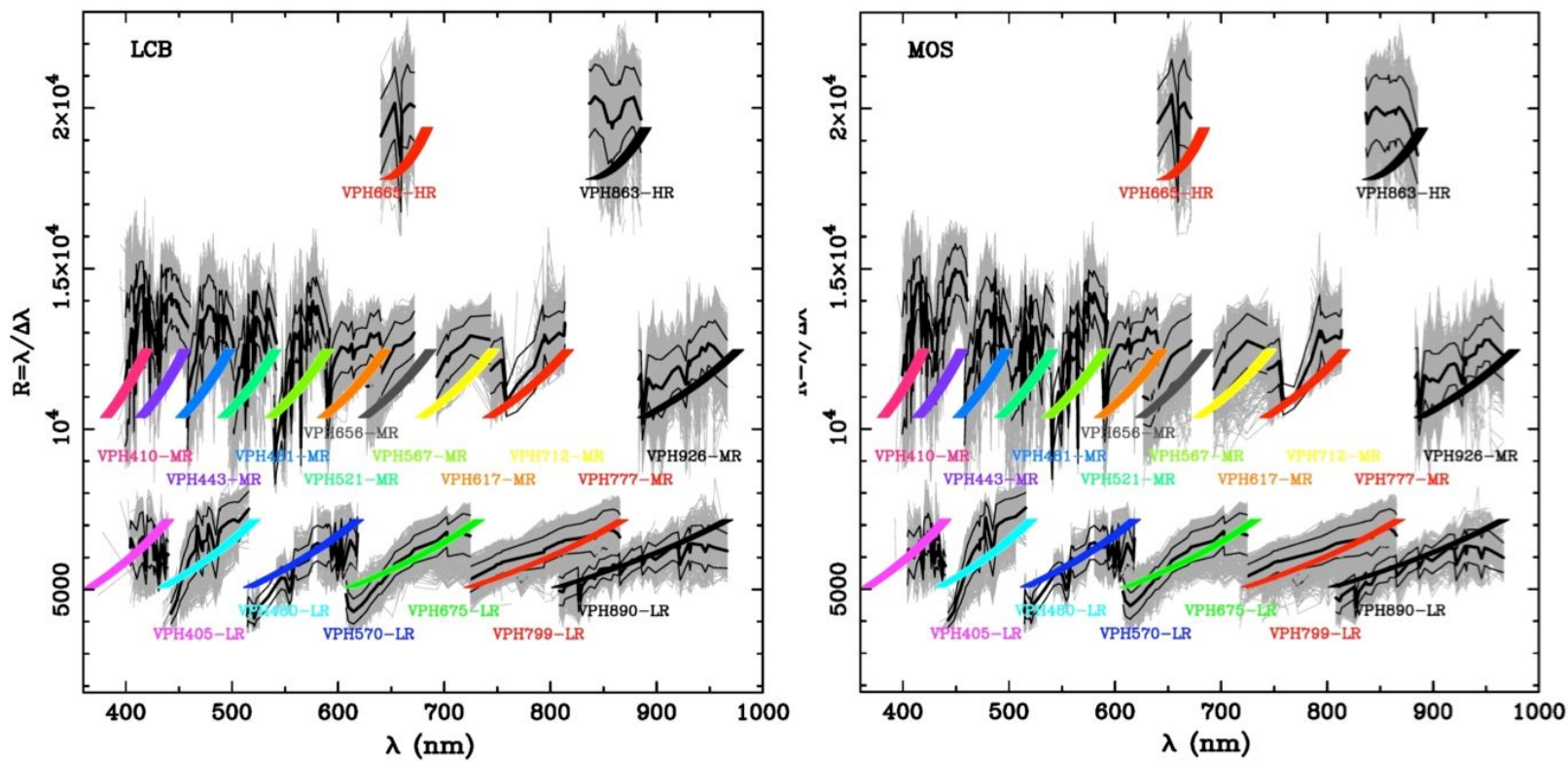

Figure 15: As-built Resolving Power of the VPH gratings in both LCB (left) and MOS (right) modes. 
We found that 4 robotic positioners (out of 92) were not performing well. Two positioners seemed to have mechanical problems. The intermittent failures of the other two seemed to be related with electronic issues. Spares were available for changing positioners and electronic cards but this maintenance task was differed to have the new Folded Cassegrain $\mathrm{F}$ auxiliary platform, needed for this kind of maintenance operations, installed at GTC (foreseen by GRANTECAN on June 2018).

The nighttime commissioning included the following tests (see [2], [3] and [4]):

- MEGARA telescope focus on lens array surface assessment.

- Optical-axis alignment assessment.

- MEGARA Folded-Cassegrain: Dynamical Tilt checking.

- Validation of the Telescope $+A \& G$ pointing corrections.

- Dynamical Fiber MOS test.

- LCB and Fiber MOS pointing tests.

- Spaxel area and distance between spaxels (spaxel size).

- Field of View.

- Spectral performance.

- Throughput and flux uniformity.

- LCB Fast-mapping test.

- Spectroscopic limit test.

During night-time commissioning, 2570 images (1,598,540 spectra) were taken with the LCB and 847 images (544,621 spectra) with the MOS (see Figure 16). In total, more than 2 millions of spectra (1.2 millions on astronomical targets; see [2]) were obtained.

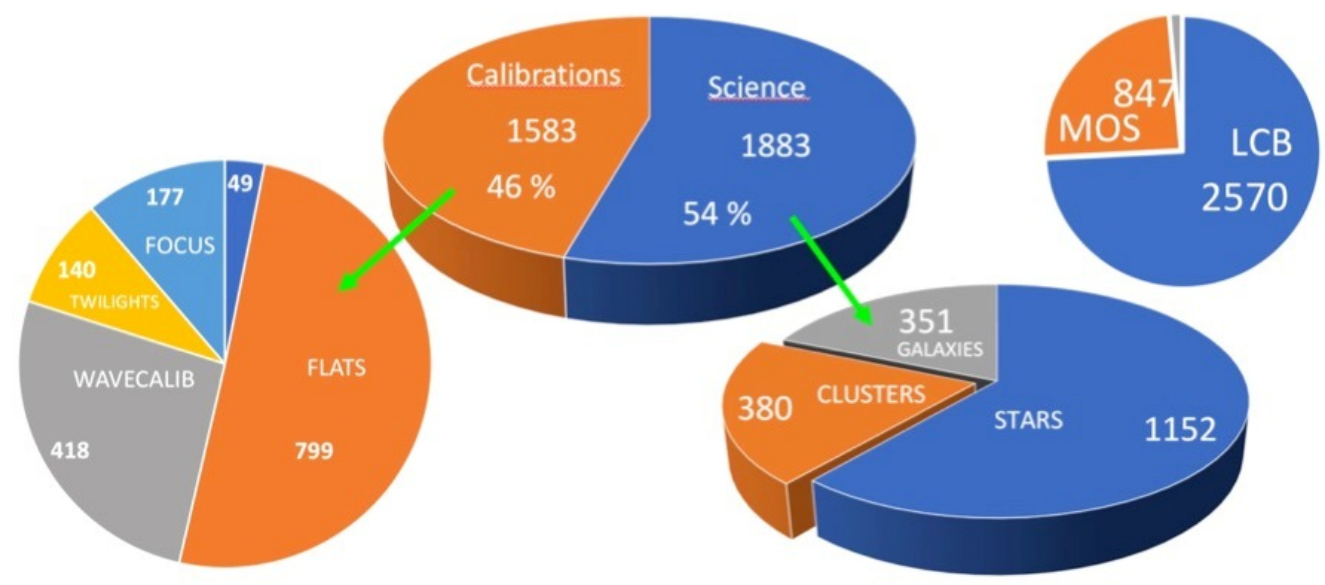

Figure 16: Night-time commissioning statistics.

The analysis of these images allowed to conclude that MEGARA is fulfilling specification and was ready to enter in operation (see more details on the instrument performance in [1]). MEGARA has already been offered to the GTC community in the call 2018B to enter in operations in ordinary scientific operations in July 2018. 


\section{CONCLUSION}

This article summarizes the plan that was followed to disassemble, pack, transport, integrate and commission MEGARA at GTC. The integration and commissioning plan was carefully prepared and agreed with GTC well in advance. The approved plan was successfully followed with very minor modifications. MEGARA was verified to be ready for starting commissioning at the end of the integration period and, then, to be ready for entering in operation at the end of the commissioning period.

The previous exhaustive instrument characterization performed at laboratory, the essays carried to test the fiber link integration, a well thought out integration and commissioning plan, the support of the GTC operation team and the devoted dedication of the MEGARA team were the key of a really successful integration and commissioning plan.

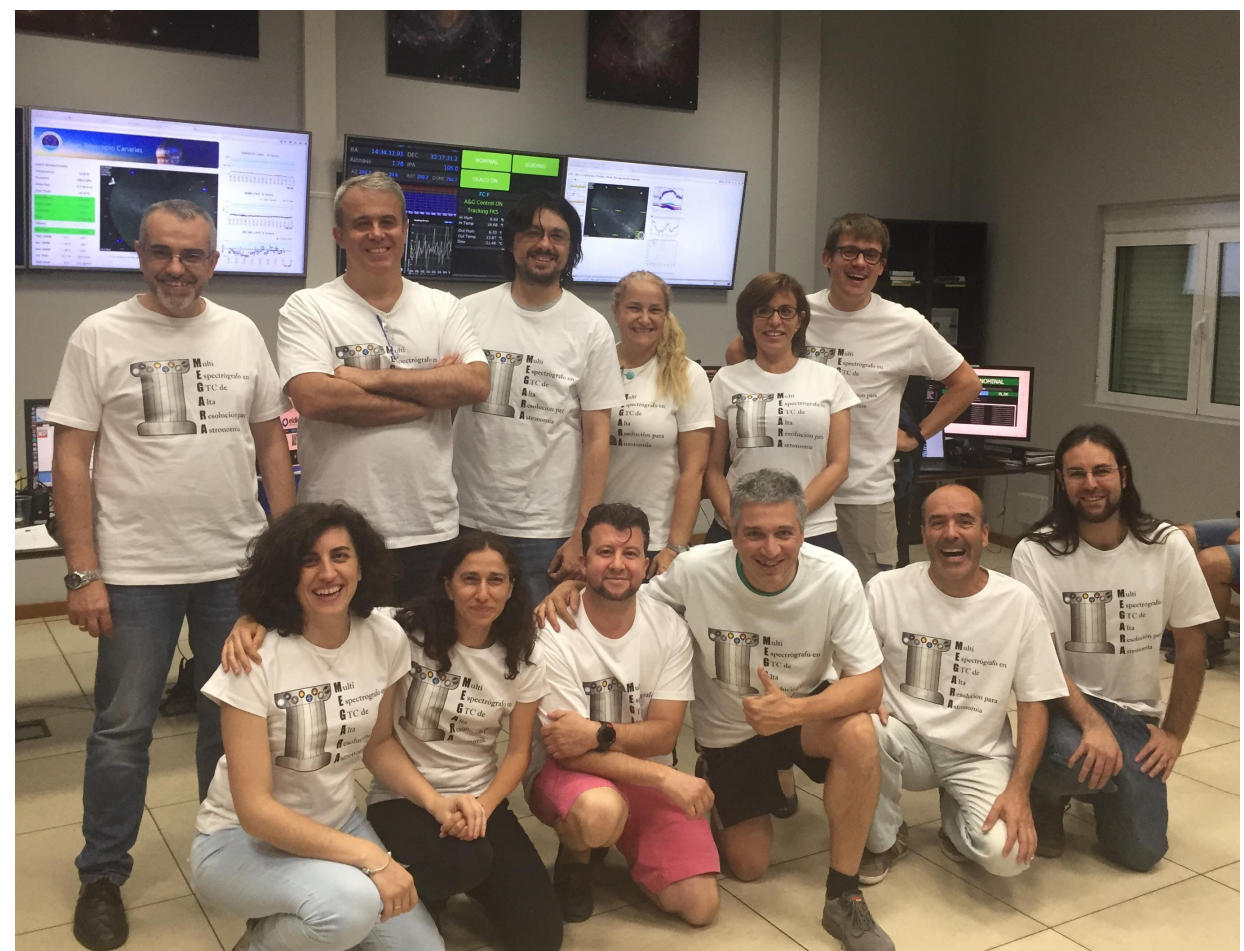

Figure 17: MEGARA team at the GTC control room during the $2^{\text {nd }}$ nighttime run.

\section{REFERENCES}

[1] Carrasco, E. et all, "MEGARA, the R=6000-20000 IFU and MOS GTC" Proc. SPIE 10702-42 (2018)

[2] Gil-de-Paz, A. et all, "First scientic observations with MEGARA at GTC" Proc. SPIE 10702-43 (2018)

[3] Gómez-Alvarez, P. et all, "MEGARA observation preparation and Quick Look software" Proc. SPIE 10707-56 (2018)

[4] Pérez-Calpena, A. et all, "MEGARA MOS: where are my positioners and fibers pointing to?" Proc. SPIE 10706-82 (2018)

[5] Pérez-Calpena, A., et al., "MEGARA. High-precision alignment system for gluing fibers and microlenses", Proc. SPIE 9912-194 (2016)

[6] Maldonado-Medina M. et al., "MEGARA spectrograph Mechanics and Opto-mechanics in the AIV phase", Proc. SPIE 9908-327 (2016).

[7] Martínez-Delgado, I. Proc., "The large MEGARA pupil elements: assembly, tests, and performance", Proc SPIE 9912-149 (2016). 